\title{
For a Pedagogy of Care
}

\author{
Luigina Mortari \\ University of Verona
}

\begin{abstract}
Today, philosophy as well as other sciences identifies care as a primary concept to reflect upon, and if we contemplate our own experience, the ontological and existential primacy of caring becomes apparent. Starting from these premises, it is fundamental to reinterpret education from the perspective of the concept of care. To contribute to the development of this pedagogical debate, the aim of this paper is to identify the ways of behaving which qualify the competence of an educator as capable of providing care. This is a central pedagogical question; indeed, since the practice of care occurs in relationships where the educator is the subject responsible for ensuring that the relationship is permeated by care. As such, a core task of pedagogical reflection is identifying the relational postures which shape good care.
\end{abstract}

Keywords: ethics of care, pedagogy, education, educational practices and postures

\section{Introduction}

There is a need for the theoretical research on pedagogy to investigate what Heidegger defines as questions of considerable importance - that is, those questions that are essential to pedagogical reflection - in order to define the essence of an effective educative practice. Today, both philosophy-precisely moral philosophy_and other sciences, such as nursing, identify care as a primary concept to reflect upon, and if we contemplate our own experience, the ontological and existential primacy of caring becomes evident. Starting from the assumption that care is ontologically and existentially fundamental, it is argued that care should be the core concept of a philosophy of education. From this perspective, some philosophers of education, like Noddings, have considered care as the core concept of their reflections, thus hypothesizing the possibility of an institutional caring. In order to contribute to the development of this pedagogical debate, the aim of this study is to identify the ways of being which qualify the competence of an educator as being capable of care, or "the behavioural indicators of caring" (Noddings 1984, 12). This is a central pedagogical question; indeed, since the practice of care occurs in relationships and the educator is the subject responsible for ensuring that care permeates the relationship, then a core task of pedagogical reflection is identifying the relational postures which shape good and right care—-that is, care which facilitates the flourishing of the human being.

\section{Structure of the Discourse}

This study is structured in two parts: a preliminary part aimed at drawing the theoretical foundations of an educative care and a core part aimed at explicating what constitutes the good practice of care.

Luigina Mortari, Ph.D., full professor of Epistemology of Qualitative Research, Head of the Department of Human Sciences, University of Verona, Italy; main research field: Qualitative Method of Inquiry, with a specific interest in Phenomenological and Hermeneutic Methods, and the Philosophy of Care. 
As stated above, the first part of this study is a theoretical enquiry into care. The first step in this process is conducting a philosophical analysis aimed at attesting that care is a primary dimension of human life. This part of the discourse is grounded in Heideggerian philosophy in its analysis of "being there" (Da-sein) (Heidegger 1996). According to Heidegger, care is an existential and basic ontological phenomenon in the sense that the fact of "being there" is in itself caring; that is, caring is that condition to which human Da-sein belongs for its lifetime. The second step grounds the conception of education as care in an etymological analysis of the Latin term education. The third step is aimed at interpreting education as care, starting from the Socratic concept of education as epimeleia (the Greek word for care); in the Socratic thought, education is conceived as "caring for youth" and leads to promoting the capability of "caring for oneself" in young people.

Following this basic analysis, the second part of this study consists of identifying the essential qualities of caring behaviour and the ethical substance of good educative care. The questions are as follows: What constitutes good care? What are the good relational postures of care? What are the practices that constitute the essence of care?

\section{The Preliminary Part: Theoretical Foundations of Educative Care}

\subsection{The Primacy of Caring}

Caring is important to existence both at an active and a passive level. Care is necessary at an active level because human life is not fixed or predetermined; rather, it requires effort to give shape to a life. In other words, living is caring throughout one's lifetime. Further, care is necessary at a passive level because, in order to develop one's existential possibilities, one must receive care. In other words, without being cared for, it is difficult to have a good life.

\subsection{An Etymological Analysis of the Term "Care"}

The practice of care is essential to the growth of a civilisation. We can also draw this assertion from an etymological analysis. It is generally thought that the verb "to educate" comes from the Latin word educere, which means to pull out or bring to light. However, it is more correct to affirm that "to educate" comes from educare, which means to bring up or nourish, to care for, and to educate, instruct or form. Furthermore, if we consider the word "culture," we find that it comes from the Latin colere, which means to cultivate, dwell, or take care of. Colere indicates an attitude of carefulness (Arendt 1961). Therefore, we can say that the practice of caring is the foundation of a civilisation. Moreover, Cicerus used colere (i.e., to cultivate or take care of) to coin the expressions excolere animum, which means to cultivate the mind, and cultura animi, which refers to a cultivated mind (Arendt 1961). According to some scholars, the expression cultura animi was coined as a translation of the Greek paideía. This interpretation could reinforce our idea that there is a close relationship between care and education.

\subsection{The Originary Meaning of Educative Care}

Since the concept of education as care is at the root of Western culture, it is useful from a pedagogical standpoint to deepen the concept of educative care, starting from the Socratic concept of education (paideía) as epimeleia (the Greek word for care).

Socrates is known to have made the first speech on education which expressed the concept of caring as the basis for education. In Eutiphrones, Socrates states that "the best thing one can do is to care for the young, so 
that they can grow in the best possible way" (Plato, Eutiphrones, 2d). In this case, the term "care" means a way of being that benefits the person who is the object of caring attention (Plato, Eutiphrones, 13b).

The first task of caring that educators should be concerned with is helping young people to not be concerned with wealth, fame, and popularity but with caring about wisdom, truth, and the soul, as these are the most important things in life. They are the things that cannot be renounced in order to authenticate life, since they allow one to "become the best and wisest person possible" (Plato, Apology of Socrates, 29d-e e 36b). Alcibiades further defines the concept of caring in the following terms: Education is caring that the other learns to care for him/herself. Caring for oneself means giving an ethical and aesthetic meaning to one's life; that is, looking for directions of meaning that can authenticate one's existence.

The purpose of education lies herein: to help students cultivate the desire to care for themselves - that is, to accompany them through the process of building the cognitive skills and emotional attitudes they will need to be self-sufficient and enthusiastic on the path of their existence, so that their lifetime will be the actualisation of a process of bestowing sense.

\section{The Core of the Discourse: Qualities of Good Care and Its Ethical Substance}

\subsection{Two Indicators of Care}

The previous theoretical analysis makes it possible to investigate what constitutes good educative care. If we assume that care is a practice (Bubeck 2002), or more precisely a relational practice, in which an adult, who is responsible for the relationship, facilitates a young person's care for life, it becomes fundamental to understand what constitutes a good relationship of care. To pursue this understanding, we use as a reference Noddings's theory, according to which receptiveness and responsiveness area are the key behavioural indicators of good care.

(a) Receptiveness: to be receptive means to assume a passive posture in which it is possible to listen to others. Activating a deep capability of listening is necessary in order to understand the existential needs that the other is trying to communicate (Noddings 1984, 24). Receptiveness implies a passive posture in which the one caring allows the cared-for to communicate his/her experience and needs. Such a passive posture is a condition for one's active positioning in the relationship.

(b) Responsiveness: to be responsive means to adequately answer others. Winnicott speaks of a live adaptation to the needs of the child (Winnicott 1987). There is a close relationship between receptiveness and responsiveness, in the sense that through a receptive posture one should understand the needs of the other and through a responsive posture, one should carry out those actions which correspond to these needs, to promote the other's well-being. To be responsive to the needs of the other means to confirm that person's worth and the importance of what he/she thinks and feels, when someone is recognised, then he/she realises that he/she exists. Indeed, existence is not a lonely act; a person exists if he/she feels that he/she is in the gaze of others. Thus, responsiveness implies an active and watchful presence supported by an ethical attitude that consists of the readiness to expend oneself and make oneself available (Noddings 1984, 19).

\subsection{The Relational Postures of Good Care}

To construct a good pedagogical theory which can be useful to educators, it is not sufficient to identify the key behavioural indicators of care; indeed, it is necessary to understand what the relational postures are which enable an educator to be receptive and responsive. This is the key pedagogical question of the study. 
On the basis of an analysis of the ways of cultivating a relationship of care, which characterise the paradigmatic cases of care (motherhood, friendship, nursing), the essential relational postures of a caring educator are as follows:

(a) Being available both at a cognitive and an emotive level: Receptiveness and responsiveness imply a sensitive disposability, both emotive and cognitive, that consists of a readiness to bestow and spend our emotive and cognitive resources in relationships with others. Disposability is the way of generosity (Noddings 1984, 19). The practice of care is often misinterpreted as simply being emotional availability. Certainly, the ethics of care re-estimate emotions, because these emotions constitute a fundamental element that is necessary to grasp a fine and deep comprehension of the other's experience-a comprehension both of what the other wants to say and what he/she is unable to say. Without a feeling of intense sharing, there is no real understanding of the other. However, we must not forget that care also requires thinking to become an intelligent practice. Sara Ruddick discusses specific "maternal thinking," because an "adequately dedicated mother” has an intelligent outlook on the experience of the other (Ruddick 1989). In the practice of care, thinking means being attentive to the uniqueness of the other, or thinking "with special regard for the particular person in a concrete situation" (Noddings 1984, 24). Therefore, in the practice of care, disposability proves to be emotive thinking or, in other words, an intelligent feeling.

(b) Having empathy: Being able to feel the reality of the other means being capable of empathy. Empathy is that co-feeling that allows one to perceive the feelings of the other. It is necessary to point out that empathy does not involve projection but receptivity. When one is capable of empathy, then the experience of the other - that is, what we have not experienced and never will—becomes an element of our own experience, although it is not our own experience (Stein 2002). In an empathetic relationship, our openness to the other is never a symbiotic fusion or a loss of borders between oneself and the other; rather, it is a mutual listening that safeguards the otherness of the other and his/her unrepeatable uniqueness. In order to develop an empathetic attitude, it is necessary to bracket our own self and assume a radical receptive posture; only in a passive condition can the mind become permeated by an "attentive quietude” (Noddings 1984, 31).

(c) Being attentive: Attention is receptivity taken to the extreme, where it becomes the deliberately intense concentration on a phenomenon (Zambrano 2007). It is a patient, loving regard directed upon a person (Murdoch 1970, 40). In order to care, it is necessary to develop an intensive and open attention toward the other. Attention with care consists of being capable of focusing on the other so as to grasp his/her original way of coming into being. Focusing one's attention on the other is possible if one steps out of oneself-that is, out of one's own personal frames of reference - to consider the other's point of view (Noddings 1986, 24). Thus, attention requires that one ignore one's own expectations and desires in order to make room for the other. This underlines the necessity of the good in the care and, in this sense, attention is an ethical posture.

(d) Giving security: As Winnicott explains, in the first phase of life, in order to give safety to the child, the capability of holding in one's arms is essential (Winnicott 1987, 34-35). To be capable of holding in one's arms means to welcome and safeguard the other, to give him/her scaffolding. A mother who is able to hold her baby in her arms accepts him/her completely and makes him/her feel whole and safe, thereby enabling the child to feel the continuity of his/her being. Later, offering safety means knowing how to give constant help-that is, being present when it is necessary. Thus, the cared-for person should perceive that the one caring is reliable.

(e) Being unobtrusive: The educative practice should be inspired by the principle of respect for the other in his/her differences. In order to safeguard the other, it is necessary to learn to be unobtrusive - that is, activating 
a kind of solicitude that should be continuous but discreet. The other should rely on the people doing the caring, while feeling that they are not invading his/her vital space. An unobtrusive presence consists using discretion in helping the other. In this kind of presence, the subject places him/herself in the relationship by standing aside. Heidegger defines this kind of care as authentic (Heidegger 1996), and distinguishes it from care where the subject takes the place of the other in his/her personal task of caring for his/her life. Everybody has the responsibility of shaping his/her lifetime. No one can evade their ontological responsibility; if that happens, the educative relationship will fail. Taking the place of the other, taking on that care which is constitutively proper to the other, expels the other from his/her proper place, in the sense that it takes away one's main responsibility, making the other dependent and capable of being dominated. Authentic caring is, rather, sustaining the other in an autonomous search for ways of caring for himself/herself. The unobtrusive attitude is guided by the ethical principle of respect, which is having special regard for the other, understood as intense but discreet attention.

(f) Being capable of waiting: Having respect for the other, so that he/she can realise his/her own proper way of being, requires that the one caring be capable of waiting - that is, giving enough time to the other to exist on his/her own terms. The opposite of waiting is expecting. Expecting is forcing others in a direction and according to a rhythm which is imposed on their being. Waiting, however, is not renouncing the educative action but giving space to subjectivity.

(g) Cultivating positive and healthy sentiments (hope, acceptance, trust, tenderness, confidence): As Heidegger states, the human being is always in the existential way of attunement (Heidegger 1996, 126). With the term attunement, Heidegger identifies the mood, or being in a mood. Since our mood conditions the quality of our lives in the world, it is essential to uncover which moods characterise the good practice of care. I think that a necessary condition for good care is when the caring person is capable of nourishing the caring relationship with healthy, vital sentiments. Giving importance to sentiments does not mean falling into an irrational discourse on education. In modern culture, which has Cartesian roots, sentiments are viewed as irrational components of the mind to silence and bracket, since they pollute both scientific research and ethical thinking. Otherwise, our lives are witness to sensitive changes in paradigms, which recognise the value of emotions and define them as "reasonings of the heart" (Bateson 1972, 482), indicating the intelligent capability of feeling. According to Martha Nussbaum, sentiments are intelligent components of the soul; they not only indicate directions of meaning for "good human life" but facilitate a deeper understanding of moral dilemmas (Nussbaum 1996). Indeed, in many situations, the ability to listen to our own emotions offers us a deeper understanding of the problems we face. In the book Le Petit Prince (The Small Prince), the fox explains to the small prince that the secret is quite simple: One can only see well with one's heart (Saint Exupery 1946). Positive healthy sentiments are necessary not only to make the educative relationship more vital but for grounding the deliberative thinking which orients our actions when we must face a complex problem. Education implies that the educator is continuously required to make decisions in situations of great uncertainty; in these problematic cases, thinking needs to nourish itself not only through operational logic but also through emotive sensibility. Yet sentiments are important also in constructing theories of education. Pedagogical wisdom is not the expression of a pure, neutral rationality; it needs both reasons of the heart and the intellect. It needs to nourish itself through maternal reasoning. It is necessary to point out that a caring relationship can be quite a problem at the emotional level, because the caring adult must also constantly face emotions such as hate, fear, sorrow, impatience, resentment, and despair. Thus, caring work requires the adult to engage in an 
experience of self-education, where he/she learns to avoid these emotions and guide the behaviour. "Caring for children requires attentiveness to self-care, self-understanding, and self-formation” (Bowden 1997, 33).

(h) Being reflective: Caring for the other also means caring for the life of the mind, and that means cultivating a relationship in which the educator gives meaningful cognitive experiences to the cared-for. In order to identify the essential qualities of care for the mind, I refer to the Socratic practice. According to Socrates, educating one's mind means learning to "know oneself," because only by knowing who we are can we understand what we need to better ourselves (Plato, First Alcibiades, 128e): It is through knowing ourselves that we can learn how to care for ourselves; whereas, if we don't know ourselves, we will never be able to do it (Plato, Alcibiades Primo, 129a). To help the other understand him/herself more profoundly, it is necessary to encourage him/her to examine his/her thoughts, in the sense of submitting to a detailed scrutiny of every corner of his/her mind (Lachetes, 188a). This education directed at self-analysis occurs when the educator interrogates, examines, and confutes the other. Educating the mind means dialoguing with the other, and the dialogue must be aimed at unfreezing crystallised beliefs, or rousing the other to doubt any idea. Since self-analysis is an exhausting job, the educator must almost lead the person by hand until he/she has a good understanding of his/her cognitive life (Lachetes, 187e). Yet the educator must doubt the other in a balanced way. Acting with balance means considering both one's cognitive and emotive resources, and then deciding how to dialogue with them. When the doubting approach is not balanced, then the other person tends to escape the educative action, since he/she perceives it as unsustainable. This happens to Eutiphrones, who, when faced with Socrates' proposal of restarting the detailed conceptual analysis of sanctity in which he is involved, replies, "Another time, oh, Socrates. Now I am in a hurry. I must go elsewhere and it is time to go” (Eutiphrones, 15e).

These relational postures of care will be subject to a detailed phenomenological analysis aimed at identifying the essence of these postures. The frame of reference for building this central part of the discourse can be found in the philosophies of Martin Heidegger, Emmanuel Lévinas, Edith Stein, and Maria Zambrano.

\subsection{The Ethical Substance of Good Educative Care}

In order to explicate the essence of the educative posture and practice of care, it is necessary to analyse its ethical substance. There are different ways of caring: from simple caring for the other, to mindful consideration of his/her health and happiness (solicitude), to dedication and devotion (Mayeroff 1990). Good educative care requires the educator to devote mindful attention to the other showing solicitude. This kind of relationship has an ethical substance which consists of the following:

- being responsible

- having respect

- wishing for what is good for the other; being giving

These are the essential qualities of what we can define as "giving proper care" (Plato, First Alcibiades, 128b). The last part of the study investigates these three ethical sides of care in depth.

Good practice of care means that the carer is responsible for the other, since he/she is aware of the other's dependence - that is, he/she is in need of the help of the carer in order to preserve and flourish in his/her life. Caregivers explain that perceiving such dependency reinforces the necessity of acting responsibly, and accepting this ontological necessity helps the caregivers act in an ethical way, by finding the right and good way to meet the vital needs of the other. According to Lévinas, it is not an abstract duty generated by logical arguments which calls us to moral responsibility; it is finding oneself in the physical presence of another 
(Lévinas 1969). "Ethicness" is not consequent to the application of some abstract and universal principles generated by a theoretical reflection; rather, it arises from a concrete, embodied encounter with the other. It is the face-to-face relationship which obliges one to be responsible. When we are confronted with the face of the other, writes Lévinas in Totality and Infinity, the nakedness and vulnerability of that face call us to an infinite responsibility. It is when we recognise the priority of the other that we become responsible: "Prior to any act, I am concerned with the Other, and I can never be absolved from this responsibility" (Moran 2000, 348). The empirical data analysed in light of Lévinas's thought show that good care is not based on contractual ethics, where isolated individuals learn rules and then apply them to the reality; instead, the source of the carer's responsibility is the lived experience of the problematic condition of dependency on the other. We discover our ethical responsibility not as an effect of recognising the moral rules but in the starving face of a child or in the lost gaze of an immigrant. Many caregivers as well as theorists of care, when required to explain the quality of good care, speak of "devotion." This posture of being-with-the-other has its source in the awareness that the other has an infinite value which, in turn, demands infinite responsibility. Speaking of my responsibility for the other as infinite is not equivalent to affirming that it implies an absolute self-sacrifice. Infinite responsibility is not that which is boundless and demands a supererogatory behaviour, because if I nullify myself in a sacrificial approach, there is no longer any morality, since the ethical subject is lacking. Instead, infinite responsibility is that which is not anticipated as being bound in rules and codes but defines itself in relationship with the contextual and unique meeting with the other.

Lévinas speaks of the other as one who has the "statute of infinity" (Lévinas 1969, 201). This infiniteness of the other is an infiniteness of value; his/her presence is one which overflows with value. Welcoming the other in his/her infiniteness of value means safeguarding him/her. This infinite value makes the other inviolable and sacred. For a mother, her child is inviolable; for a friend, his/her friend is inviolable; for a teacher, the student is inviolable. However, because he/she is dependent, his/her infinite value is vulnerable. Then, good care occurs when one knows how to safeguard the infinite value of the other - that is, his/her otherness - and this requires being capable of respect. Furthermore, the carer perceives the necessity of having respect for the other because he/she feels his/her vulnerability. Nussbaum states that vulnerability is a kind of human excellence (Nussbaum 1986). However, if we interpret the relationship between vulnerability and excellence in light of the theory of care, we can maintain that the primary way of human excellence does not consist of vulnerability itself but of caring for vulnerability. In the philosophical theories which investigate the ethical posture of respect, placing the willingness to act according to this ethical principle frequently recurs with the perception of the other in his/her value. This is what Aristotle states in Rhetoric (II, 1, 1378b), according to which, "lacking in respect is the effect of an opinion relative to something which appears as valueless." The theory which conceives a respectful posture as a consequence of the perception of the value of a being has been developed recently by certain ecological ethics which, in order to modify the instrumental and utilitarian structure of our culture in a radical way, maintain that it is necessary to encourage an ontological conception according to which every being has an intrinsic value. This theory is based on the assumption that the ontology of the intrinsic value should directly perform as an attitude of respect (Taylor 1998). Just because this theory considers the ethical posture to be a direct consequence of the acquisition of a concept, it has the limitation of being too intellectualistic. However, in the practice of care, respect is not an abstract principle whose importance is perceived through logical arguments but where the caregiver immediately feels its ontological necessity because he/she is participating in a face-to-face relationship with the vulnerability of the other. 
Good care, which requires meeting the needs of the other, may be practised at varying levels of involvement: The caregiver can simply look after the other, can be more careful by worrying about the other, or can-to use Heidegger's expression—give "attention and dedication” (Heidegger 1996, 185). When care is realised as an act of dedication to the other, it requires that much of one's time and energy be dedicated to the other. This act of dedication is an act of giving, because nothing is asked for in exchange. Indeed, a good caregiver dedicates his/her time to the other with the sole aim of promoting his/her well-being, without expecting anything in return. Authentic care is infused by the posture of giving; indeed, in an asymmetrical relationship of care, where one is dependent, in order to meet the needs of the other, the caregiver must give without asking for anything in exchange. We can define this way of acting as being infused by the logic of giving. To give attention and dedication is to give time to the other. Since life is time, giving time to someone is giving them what is essential. Giving time is the best kind of care because "this is the only good that not even a grateful person can repay” (Seneca, Epistulae, I, 3). Precisely because life is time, giving time to the other is giving that which is essential. Giving attention and dedication to the other does not mean losing oneself in a supererogatory way but, instead, being capable of a solicitude that allows the caregiver to make the experience one of the authentic meaningfulness of existence. The widespread commercial culture teaches us to strive for maximum efficiency, and thus not waste time, and in keeping time for ourselves, we waste time. Those who practice giving as their way of being feel that they are outside of the common order, but they also know that only by being out of the utilitarian order is it possible to gain a sense of existence. From an Aristotelian perspective, the sense of ethics involves looking for good-that is, what allows us to live a good life (eúdaimonía). The act of giving is moved by the idea that one’s own well-being lies in a necessary relationship with that of the other. Then, to dedicate oneself to the other is not a sacrificial act; rather, it is the way to realise oneself. When the caregiver perceives that he/she is doing what is good for the other, this is sufficient for making him/her feel the pleasure of acting with care. There is indeed a pleasure in giving in the practice of care which is extraneous to any logic of exchange. According to Aristotle, "happiness being the most beautiful and best of thing is also the most pleasant" (Eud Eth I, 1214a 5-10); for those who practice care according to the logic of the gift, the pleasure of happiness is seeing the happiness of the other. Every human being aims at living a good life - that is, a life which is worth living. This is what Aristotle means when he states that human beings seek eúdaimonía - that is, the happiness that comes from "living well” or "acting well" (Nic Ethics, I, 1095a 18-19). One who dedicates oneself to care shows an ethical conception which is similar to the Aristotelian one, according to which living well and acting well are one and the same thing, and acting well means facilitating oneself and others in the search for good. Since the search for good is the most ethical question, we can say that the practice of care is an ethically informed practice.

\section{Conclusion}

The core of the discourse of this study is fundamental for advancing a theory of education which indicates to educators the ways of acting by which it is possible to implement a good educative practice of care. The intention which orients the practice of care is the same one which underlies the philosophy of Lévinas: feeling the irreducible priority of the other. Care is a practice, and thus its essence should comprise ways of being. What is possible to assert through a phenomenological enquiry into this practice, as explained in this article, is that these ways of being are ethically dense. Therefore, it is important to reflect on the proper ethical ways of being as the good practice of care. Renouncing the discussion of the ethics of care does not mean relegating 
care to a realm "outside of ethics" but avoiding speaking of ethics as a set of rules and, instead, focusing on the "ethicalness" embedded in the ways of being which characterise good care.

\section{Works Cited}

Arendt, Hannah. Between Past and Future: Six Exercises in Political Thought. New York: The Viking Press, 1961.

Aristotle. Rhetoric. Trans. W. Rhys Roberts. New York: Modern Library, 1954.

---. Nicomachean Ethics. 2nd ed. Trans. T. Irwin. Cambridge: Hackett Publishing Company, 1999.

Bateson, Gregory. Steps to an Ecology of Mind. San Francisco: Chandler, 1972.

Bowden, Peta. Caring. London: Routledge, 1997.

Bubeck, Diemut Elisabet. “Justice and the Labour of Care.” Eds. Eva F. Kittay and Ellen K. Feder. The Subject of Care. Feminist Perspectives on Dependency. Boston: Rowman \& Littlefield Publishers, 2002. 160-85.

Heidegger, Martin. Being and Time. Trans. J. Stambaugh. New York: State University of New York Press, 1996 (Sein und Zeit. Tübingen: Niemeyer, 1927).

Lévinas, Emmanuel. Totality and Infinity. Trans. A. Lingis. Pittsburgh, PA: Duquesne University Press, 1969 (Totalité et Infini, Martinus Niyhoff's Boekhandel: Vitgeversmaatschappiy, 1971).

Mayeroff, Milton. On Caring. New York: Harper Collina Publishers, 1990.

Moran, Dermot. Introduction to Phenomenology. London: Routledge, 2000.

Murdoch, Iris. The Sovereignity of Good. London: Routledge, 1970.

Noddings, Nel. Caring. Berkeley, CA: University of California Press, 1984.

Nussbaum, Martha. The Therapy of Desire. Princeton, NJ: Princeton University Press, 1996.

---. The Fragility of Goodness. Cambridge: Cambridge University Press, 1986.

Plato. Complete Works. Eds. J. M. Cooper and D. S. Hutchinson. Cambridge: Hackett Publishing Company, 1997.

Ruddick, Sara. Maternal Thinking. New York: Ballantine Books, 1989.

De Saint-Exupéry, Antoine. Le Petit Prince. Paris: Gallimard, 1946.

Seneca, Lucius Annaeus. Lettere Morali a Lucilio (Trans. into Italian from Latin). Milan: Mondadori, 1994.

Stein, Edith. Finite and Eternal Being. An Attempt at an Ascent to the Meaning of Being. Trans. K. F. Reinhardt. Washington, DC: ICS Publications, 2002.

Taylor, Kylea. The Ethics of Caring. Honouring the Web of Life in Our Professional Healing Relationship. Santa Cruz, CA: Hanford Mead Publishers, 1995.

Winnicott, Donald Woods. Babies and Their Mothers. Boston: Addison-Wesley Publishing Company, 1987.

Zambrano, Maria. Filosofía y Educación. Manuscritos. Málaga: Fundación María Zambrano, 2007. 